\title{
Hepatic Intravascular Large B Cell Lymphoma
}

\author{
Katsuya Shiraki, Kazushi Sugimoto, Masatoshi Deguchi, \\ Nobuyasu Ito, Chiaki Masuda and Yoshiyuki Takei
}

Key words: intravascular lymphoma, liver

(DOI: 10.2169/internalmedicine.46.0299)

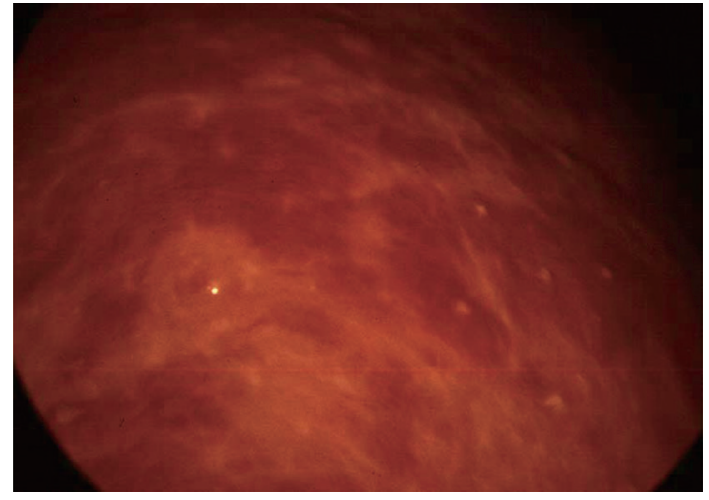

Picture A.

A 67-year-old female presented with fever and general fatigue. She had no complaints of weight loss, skin lesions and joint pain. Her past medical history was no remarkable. On physical examination, she had a temperature of 38 degrees. She did not have anemia, jaundice, neurological sign, skin lesion or lymphadenopathy. In the abdomen, moderate hepatomegaly and splenomegaly were observed. The initial laboratory investigation showed T-Bil. $1.13 \mathrm{mg} / \mathrm{dl}$, AST 84 IU/l, ALT 48 IU/l, LDH 1399 IU/l, PT 69\%. Virological markers are negative. Abdominal ultrasonography and whole CT scan showed hepatosplenomegaly. Bone marrow biopsy showed normal cellularity and architecture and no hemophagocytic histiocytes.

Therefore, we performed laparoscopy and liver biopsy. Laparoscopic findings showed hepatosplenomegaly. The liver had a slightly dull edge and a relative smooth-surfaced lobe with tiny white macules widely distributed throughout the surface. The white, partially confluent cords of tissue had no reference to the portal areas of the liver surface (Picture A). Histologically, the sinusoids were markedly expanded by an infiltrate of the abnormal lymphocytes. And nodular focus of the abnormal lymphocytes was seen in the hepatic lobules (Picture B). Immunohistochemical analysis showed that the abnormal lymphocytes were positive for

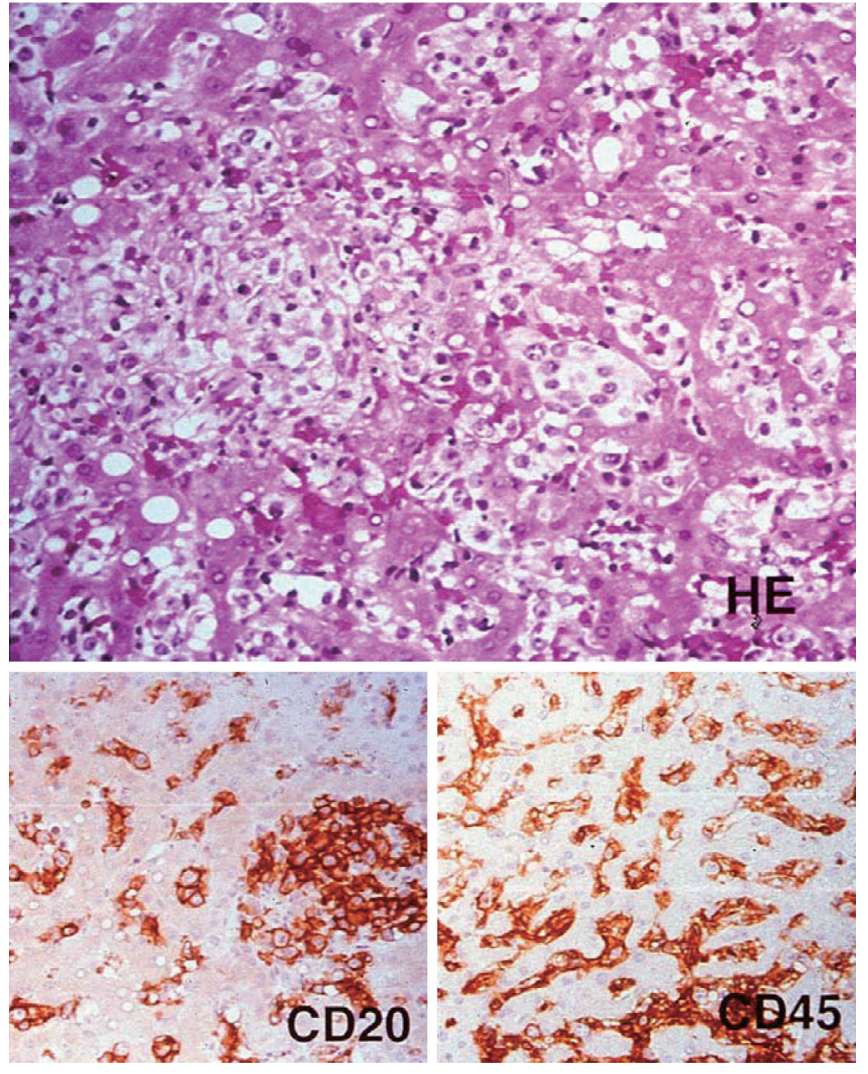

Picture B.

CD-45 (LCA) and CD20-cy (L26). Diagnosis of intravascular lymphoma (IVL) was made based on immunohistochemical analysis and a CHOP regimen was started. After the 6th cycles the patient achieved a partial clinical remission.

VL is very rare subtype of diffuse B-cell lymphoma; it is pathologically featured by multifocal, exclusive or predominant intravascular growth of the malignant cells. IVL most commonly involved the central nerve system or skin. However, a wide variety of other anatomic sites can be involved, including the kidney, heart, liver, gastrointestinal tract, 
lungs, genitourinary tract. The course of the disease is usually rapid and fatal. And majority of cases have been diagnosed at autopsy $(1,2)$. Laparoscopy-assisted liver biopsy is a useful technique to establish hepatic lymphoma involve- ment of IVL, which was not identified by either computed tomography or laboratory studies (3). Early diagnosis may allow prompt initiation of polychemotherapy which might prolong survival or be curative.

\section{References}

1. Demierer T, Dail DH, Aboulafia DM. Four varied cases of intravascular lymphomatosis and a literature review. Cancer 73: 1738$1745,1994$.

2. Baumann TP, Hurwitz N, Karamitopolou-Diamantis E, Probst A, Hermann R, Steck AJ. Dianosis and treatment of intravascular lymphomatosis. Arch Neurol 57: 374-377, 2000.

3. Sans M, Andreu V, Bordas JM, er al. Usefulness of laparoscopy with liver biopsy in the assessment of liver involvement at diagnosis of Hodgkin's and non-Hodgkin's lymphomas. Gastrointest Endoscopy 47: 391-395, 1998.

(C) 2007 The Japanese Society of Internal Medicine http://www.naika.or.jp/imindex.html 